\title{
Current Existing Dilemma in Harmonics Teaching and Countermeasures
}

\author{
Zhixiong $\mathrm{Xu}$
}

College of arts, Jingchu University of Technology, Jingmen Hubei, 448000, China

Keywords: Harmonics, Teaching, dilemma, Countermeasures.

\begin{abstract}
Harmonic is an important technological theory after basic music theory, the significant basis to master composition and other relevant musical theoretical courses. In addition, it has very close relation to the other musical courses' learning, which is the important technical content that professional musicians must be skillful and master. Since the birth of harmonic, there are still many problems that need to be solved during the practical music education. In the specific teaching, it needs to more deeply intensify the teaching of musical correlation theories, actively guide students to fully give play initiative by constantly promoting educators' capability, achieving to change passive learning to positive learning. This article analyzes the current existing dilemma in harmonics teaching and emphasizes elaborating several countermeasures to improve the dilemma.
\end{abstract}

\section{Introduction}

Since the music education started late in our country, the music major has not yet built entirely independent classroom teaching system, mainly following the traditional harmonic teaching method. The first is the harmonic teaching method to the theoretical composition major in musical colleges and universities, with cultivating theoretical and creative music talents as its major teaching objective. It could cultivate learners to fully and systematically master the creating skills and language rule of harmonic, promote learners' aesthetic judgment and ability of thinking to polyphonic music by learning and referring to the successful harmonic playing experience of the music pieces at home and abroad and cultivate learners' imagination and creative ability with all strength so as to settle solid foundation for their learning. The second is the harmonic teaching method in advanced normal universities, with cultivating music major teachers as its major teaching objective. The primary task to carry out harmonic teaching is to let learners comprehensively and systematically master the basic theory of traditional harmonic, acquaint themselves with all kinds of harmonics in the music pieces and possess favorable harmonic creative ability.

\section{Analysis of Current Existing Dilemma in Harmonics Teaching}

At present, the harmonic courses in China's colleges and universities are generally set up for one year. Due to the short learning time, there are many related problems that need urgently to be solved during teaching. It can be mainly concluded to the followings: firstly, some students don't have deep acquaintance to the significance of harmonic teaching and not enough interest. They think it is boring to learn harmonic. Since students have different basis when they enter the university, some students have no solid basic knowledge to music theory and the harmonic teaching is mainly taking creation as main teaching method, it must lead to some students losing learning interests and thus hard to experience the beauty of harmonic. Secondly, the mode of classroom teaching appears to be rigid and single, which lay particular emphasis on lecture of pure theoretical property rather than the explanation to harmonic sound effects. Thirdly, it would always give lecture to the traditional harmonic of European major key and minor key system and too little to the harmonic of five-voice 
mode in our country or the modern-times harmonic in the west. Fourthly, there is too little training to the keyboard harmonic, especially in the close integration to the piano accompaniment course, so that many learners can not match appropriate chord to the song after learning harmonic.

\section{Several Countermeasures to Improve Dilemma in Harmonic Teaching}

\section{To Practically Change Teaching Concept and Intensify Cultivation of Professional Competence}

It needs to practically change the original education concept, rationally use new conceptions of teaching materials and teaching method, positively achieve the function and value of harmonic courses, make sure about the relation between teaching and learning, emphasize students' learning, take students as the subjects to motivate their learning enthusiasm, change passive acceptance to positive learning and make students feel happily learning the harmonic courses. The author thinks, it needs to combine the learning reality to give lecture so as to promote students' acquaintance to the significance of harmonic courses. For example, once the harmonic is not so solid during playing piano accompaniment, the accompaniment can not be matched. For another example, during the process of songs being created and recomposed, once it lacks harmonic foundation, it is hard to start.

\section{Pay Attention to Pertinence Teaching of Harmonic Theoretical Basis}

During the harmonic teaching, it should positively consolidate music theory and train the specific location of primary triad in each mode. Among those who have learned the harmonics before, some still can not independently carry out the harmonic writing and analysis. Though some can write, the speed is rather slow, with general lower writing efficiency. In the past music education, there is a statement that one can truly learn a kind of harmonic after at least three times, which is still accepted by many insiders. However, there are few people that would learn three to four times of the harmonics during practice. Therefore, students should consolidate basic knowledge of music theory in advance, intensify preview before class, understand the emphasis and difficulty of each chapter by explanation in class and teachers' play and demonstration, master the best learning method from analyzing harmonic to homework, combination of exercises writing and playing, reviewing teaching contents in class. After times' learning, students could quickly master the essence of harmonic. When setting the harmonic course, it is usually after the course of basic music theory and before such course of polyphony, orchestration, etc. During this period, students are in the period of learning basic music theory but can not digest or apply what they have learned to explain music pieces. Based on the education and teaching practice for a long time, the author thinks during the teaching process of music basic theory, there is rather serious problem in the interval and chord teachings. Some students don't have flexible reaction to the interval nature and constituents. Thus quite many students have lower or even don't know those tones with more sharp and flat, such as I, IV, V level chord. Under such circumstances, harmonic teaching should grasp the key link. During the harmonic creating process, it should skillfully and quickly list the chords which are the important foundation to promote learning efficiency. On that account, it should rationally distribute the time and train learners on the chord memory according to the tonality relation, which is also an important link to promote harmonic writing ability. In teaching, it could choose $\mathrm{C}$ major, a minor or $\mathrm{D}$ major $\mathrm{b}$ minor to arrange the sequence. During training process, it should try to use verbal dialogical form as far as possible. As for the specific teaching schedule, teachers should make sure about the specific training content of one tonality, and then only after students' response speed to the chord make teachers satisfied and with rather high accuracy rate can they turn to the next training.

\section{To Give Full Play to the Important Function of Multimedia Technology}

A general problem that the past harmonic teaching faces is the teaching form too single and teaching method too old, so that there being pure theory explanation in the harmonics classroom teaching. 
Teachers always give lectures with a piano, blackboard and chalk, whose result is that learners have not enough interest in harmonic learning. After finishing harmonic exercise, they would always listen to the creating effect by the piano which would be very dull. Especially in recent years, music major in our institutions of higher learning keep expanding enrollment. In this way, harmonic teaching would always adopt presentation to group in class with more than 50 students. Due to too many students and limited class hour, most teachers can not elaborately modify students' assignments. And students are always the armchair strategists, practicing four-part harmonic like doing the math examination paper. There is no enough sound experience during harmonics teaching, thus the learners can not really master creation form of counterpoint. In harmonic teaching, it should apply multimedia courseware in class or doing exercises. By demonstrating exercises with vocal music, string music, wooden pipe, steel tube, etc. to get ideal harmonic effect, it would promote learners' learning initiative.

\section{To Increase Guidance to Harmonic Practical Ability}

At present, the harmonic teaching carried out in many colleges and universities would always ignore harmonic internship and practical training so that the harmonic course being almost the math course. Learners just immerse themselves in four-part harmonic creation. The author thinks it should integrate musical creation to harmonic teaching. As one important manifestation mode of music, harmonic is the indispensible primary technical condition to implement musical creation. Neither functional harmonic nor national harmonic could break away from harmonic analysis, harmonic writing, etc. And the harmonic writing needs to use relevant harmonic theoretical knowledge to carry out counterpoint musical creation. Certainly, it has become more and more popular to add musical creation into harmonic task teaching process, for example, the piano accompaniment could not only intensify specific application ability of harmonic theory and promote learners' cognition and comprehension to harmonic but also achieve closely connection between musical creation and harmonic teaching and promote learners' harmonic creative ability. When implementing traditional harmonic creation training, it should also take keyboard harmonic as the key point content to do practice. In this way, it could turn the chord connection in written form into specific sound effects and realize integration of learning and doing. After lecture of each chapter, teachers need to assign rational keyboard harmonic exercises and enroll songs in the musical materials into orchestration and training key point, which could cultivate students' ability to analyze and comprehend problems, promote learners' ability of impromptu accompaniment and show the teachers-training quality.

\section{To Moderately Appreciate Classics of Famous Musicians}

To appreciate classic music pieces is the important link during harmonic teaching process. It is to apply harmonic techniques of some famous Musicians to one's own creation and change to the valuable treasures, truly promoting sensibility and taste to one's own major. It needs to do harmonic analysis to each section of all or part conception in a music piece, which is of great significance to harmonic classroom teaching. By letting all students' knowing about the harmonic features of famous composers or each school, it is to explain the application method of each chord to terminate, modulate and so on as well as the conversion process of its rule, helping students to know bright style characteristic of harmonic and finally the musical characteristic or content. Only when the harmonic analysis method continually improves and develops could harmonic analysis play its own important function. After carrying out analysis to some harmonic writings, it needs to summarize the observed result and some conclusions. In order to explain development history of harmonic more clearly, it needs also to consider all kinds of relevant conditions. With this as the starting point, teachers should sufficiently consider functional sequence constructed by chord, try to fuse harmonic phenomenon into melody and beat as far as possible, ensure the effects of unessential note to harmonic and also consider the change from the tonality to harmonic rhythm, texture, etc. In this way, it can get rid of inherent teaching method to allocate chord according to regulations. 


\section{To Promote Horizontal Ties among Each Subject}

In the current harmonic classroom teaching, it should pay high attention to horizontal ties among each subject to promote teaching level. Chorus and piano accompaniment could be regarded as the most direct way for harmonic knowledge to be applied. Thus, harmonic educators should get close connection with chorus and piano accompaniment teachers, interworking with each other. The harmonic classroom teaching mainly lays emphasis on specific application of harmonic knowledge while the latter mainly explains the application of texture. In this way, it could avoid not only repetition in class but also coming apart of each similar subject, saving corresponding teaching materials and promoting learning effects. By learning harmonic, students could also learn relevant knowledge of the other two subjects at the same time and fine endless interest from them. The piano accompaniment is the organic link to harmonic theory and the practical application to harmonic knowledge. The harmonic classroom teaching also includes the analysis to piano music pieces which has rather wide range contents such as creating background of the music pieces, musical form structure, harmonic, playing characteristics, etc. All the above contents can not be taught by a single harmonic teacher. Therefore, promoting harmonic teaching quality must intensify mutually combination of many subjects in music major so that learners could get more comprehensive knowledge and realize the aim to fully improve music accomplishment.

\section{Conclusion}

To sum up, the harmonic teaching has come into our music teaching system for a long time, but it doesn't has ideal development. The author thinks only if all music educators and learners fight together could the harmonic teaching reform realize thorough improvement. Due to many subjective and objective reasons, dilemma that current harmonic teaching faces would still exist for some time. Thus, under such circumstances, teachers need to give lectures more clearly and students need to learn more proactively, adopting rational countermeasures together and reflecting maximum effect of harmonic teaching.

\section{References}

[1] Piao Ying, Conception of Harmonic Teaching Together. Musical Creation, 2014 (7).

[2] Huang Kai, Harmonics Teaching in Music Teaching. Yellow River of the Song, 2014 (10).

[3] Liu Yu, Analysis and Exploration to Teaching Status of "Basic Harmonics" in Colleges and Universities[J]. Theatrical Family, 2014 (17).

[4] Zheng Li, Content and Pattern Reform of Harmonic Teaching in Teacher's College. Yi Hai, 2015 (6).

[5] Chen Lin, Analysis and to Teaching Status of "Class Harmonics" in Colleges and Universities. My Great Stage, (9).

[6] Mao Huimin, On the Deficiency of Basic Harmonic Class Teaching and the Countermeasures. Journal of Jiamusi Occupational College, 2016 (8). 